\title{
'Always looking for a new balance': towards an understanding of what it takes to continue working while being diagnosed with relapsing-remitting Multiple Sclerosis
}

\author{
Abstract \\ BACKGROUND: The aim of this study was to gain insight into the \\ meaning of work in the everyday lives of people with relapsing-remitting \\ multiple sclerosis, and the barriers and facilitators to staying in work. \\ METHODS: Nineteen employed adults diagnosed with relapsing- \\ remitting multiple sclerosis participated in narrative interviews. All \\ interviews were transcribed and coded for thematic analysis. \\ RESULTS: For people with relapsing-remitting multiple sclerosis, \\ continuing to work was a precarious balancing act. Five themes influenced \\ this balance: becoming familiar with the disease, adjusting expectations, \\ having an understanding and realistic line manager, seeing work as \\ meaningful life activity, and strategic considerations. \\ CONCLUSIONS: People receiving a diagnosis of relapsing-remitting \\ multiple sclerosis have to refamiliarize themselves with their own body in \\ a meaningful way to be able to continue their work. Rehabilitation \\ professionals can support them herein by taking into account not merely \\ functional capabilities but also identity aspects of the body. Medication \\ that stabilises symptoms supports making the necessary adjustments. A \\ trusting relationship with the line manager is vital for this adaptation \\ process. Additionally, a match between being adequately challenged by \\ work, while still having the capacity to meet those work demands, is \\ needed, as is long-term financial stability
}


Keywords: Relapsing-remitting multiple sclerosis; Employment; Work; Qualitative research; Success factors; Interviews

\section{Introduction}

Multiple sclerosis (MS) is a chronic and unpredictable neurological condition with its diagnosis typically occurring between ages of 20 and 40 years (1). At this stage in their lives, people are often in the process of making decisions about job interests, just entering the workforce, or possibly already wellintegrated in professional life with a work history of ten or more years. There is a growing body of work focusing on the exploration of the impact of MS on employment status (2-5). Unemployment rates of 55-58\% have been observed among people with MS (4,6). Naturally, unemployment causes increased financial strain on both individuals' and public resources. In addition, the value of employment for the individual extends beyond the financial considerations of paid work. For many, work provides social legitimacy to live and it may be the principle source of personal identity $(7,8)$.

The physical and cognitive symptoms of MS represent a major barrier to employment $(2,5,9)$. The most pervasive symptom of MS, fatigue, strongly affects physical, mental and social aspects of someone's job (2). However, it has become increasingly acknowledged that the causes of unemployment in MS are more complicated than a simple relationship between symptoms and work capacity. Rather, they involve a complex interaction between disease-related factors, personal factors, and contextual factors $(3,10,11)$. As such, there is a need to study this interaction from the perspective of the person with MS in order to understand how people with MS themselves meaningfully connect the 
various aspects that play a role in their employment (12). To date, most studies are focused on the barriers to and, to a lesser extent, the facilitators for job retention among people with MS $(2,9,12,13)$. More insight into what people with MS themselves deem important for job retention and the motives and explanations they provide for succeeding in the work environment may offer more practical clues for rehabilitation practices, as well as potential avenues for further research.

This study was conducted in the Netherlands. As in other Western welfare states, disability benefits have been tightened as of late and the government increasingly encourages labour market participation of people with chronic conditions. Meanwhile, the employer is primarily responsible for occupational health and is obliged to pay at least $70 \%$ of the salary of a sick employee for up to two years. During this two-year period both the employer and the employee have to cooperate on a return-to-work plan. If the employee is still on (partial) sick leave after two years, a government benefit called 'Work and Income Act' may be requested at the Institute for Employee Benefits Schemes.

MS has several forms of presentation. This study focuses on people with MS with a relapsing-remitting disease course (RRMS), which accounts for about $80 \%$ of the people who are initially diagnosed with MS (14). RRMS is characterized by periodic disease exacerbations, i.e. it features a sudden onset of or increase in symptoms, followed by a full or partial recovery. The aim of this study was to examine the meaning of work in everyday life and the barriers to and facilitators to staying in work from the perspective of people with RRMS. 


\section{Method}

\section{Study design}

This study followed a narrative design and used semi-structured interviews according to the method of narrative inquiry. Narrative inquiry is a form of qualitative research that is grounded in hermeneutic philosophy and focuses on the understanding of lived experiences via narratives (15). Narrative inquiry enabled us to identify critical events in the process of job retention from the perspective of the person with RRMS.

\section{Setting and ethics}

This interview study of MS patients' experiences is part of a larger Dutch research project called the MS@Work study, which examines predictors of (changes in) employment status and work absenteeism in RRMS patients over a period of three years (5). The Medical Ethical Committee Brabant approved the study protocol of the interview study as a supplement to the protocol of the MS@Work study (NL43098.008.12). Participants were provided with a detailed information sheet and all participants provided separate written informed consent for the interview study.

\section{Sampling and participants}

The participants for this study were recruited from the database of the MS@Work study. The participants of that larger study were recruited from outpatient clinics in the Netherlands by neurologists and MS nurses according to the following inclusion criteria: (1) being diagnosed with RRMS according to the McDonald criteria 2010 (16); (2) being 18 years or older; (3) being currently 
employed or being unemployed for no longer than three years. Participants of the MS@Work study were separately informed of this interview study via two methods: 1) A letter was sent by mail to a randomly selected group of 40 people by the department of Neurology of the Elisabeth-Tweesteden Hospital. Twenty people responded by signing up by e-mail to take part in an interview. 2) A call for participation in the interview study was put in a newsletter that was sent by e-mail to all participants of the MS@Work study. In response, seven additional people communicated the wish to participate in an interview. The combined 27 people who had registered were all included. 19 were currently employed and eight were no longer in employment. This paper's main focus is on those participants who were still employed at the time of the study. We initially aimed for 20 interviews with employed people with MS but stopped at 19 interviews as no new themes emerged in the stories and saturation was reached (15).

\section{Procedure}

Data gathering took place between September 2015 and April 2016. The interviews were conducted by the first author in the homes of the participants. The participants were all from middle class backgrounds and were living in different cities across the country. The interviews lasted between 40 and 95 minutes, with an average duration of 61 minutes. The interviews were semi-structured and started off with a question about the participant's occupation. Topics introduced by the researcher were: the process leading up to the diagnosis of MS, the participant's response to the diagnosis, disclosure of the diagnosis in the workplace, the role of MS in performing professional tasks, important people and decisive factors that helped them remain at work, the meaning of work, and future prospects regarding work. The interviews were relatively open and the 
participants could choose to focus more on certain aspects or to introduce other topics. Table 1 shows the participants' demographics.

\section{Table 1}

\section{Data analysis}

Upon their completion, the first author and a student assistant transcribed the interviews verbatim with all identifiable information removed from the transcripts. The transcriptions of the interviews were analysed following a thematic approach using the method of narrative inquiry. All narrative inquiry is concerned with content ('what' is said), but in thematic analysis the content is the exclusive focus. This is in contrast to structural analysis, in which attention is also paid to 'how' something is said, 'to whom' it is said and 'for what purposes' (15). Thematic analysis matched our research aim and involved the following phases: familiarization the with data, generating the initial codes, searching for themes among codes, and finally reviewing, defining, and naming themes (29). Writing a narrative report of each interview facilitated the process of familiarization with the data. To ensure the validity of the research, the report was sent by e-mail to the participants for member checking. In addition to checking whether the narrative corresponded to their experiences, participants were asked to give a title to their story (17). After some minor changes, all participants agreed with the report. Six participants could not come up with a title. The titles of the 13 stories are listed in table 2. Subsequently, the transcripts were imported into a qualitative data analysis program (ATLAS.ti. version 1.0.49). The first author coded the transcripts by assigning codes to the text based on words or phrases. Multiple coding was applied to a part of the 
interviews to enhance inter-rater reliability (18). The second and fourth author cross checked coding strategies and interpretations and their insights were discussed. Subsequently, the first author refined some of the codes and compared all codes to identify broader categories of subthemes and key themes. The list of key themes and subthemes was discussed with all three other authors. Since only the first author was trained in qualitative analysis, the whole process was also discussed with peers of the University of Humanistic Studies with extensive experience in qualitative research.

\section{Results}

The thematic analysis revealed 5 themes. These were:

(1) Becoming familiar with the disease;

(2) Adjusting expectations;

(3) The understanding and realistic line manager;

(4) Work as meaningful life activity;

(5) Strategic considerations.

The themes and subthemes are presented in table 3 and will be further explored below, illustrated by quotations.

\section{Table 3}

\section{Becoming familiar with the disease}

The process leading up to the diagnosis was different for everyone. Some had received a diagnosis of MS within a few weeks after the first symptoms occurred. For others the diagnosis provided an explanation for previously 
unexplained, longstanding symptoms. All stories started with the participants describing how they had noticed strange bodily sensations and the realization that something was wrong. It involved sensations such as numbness, tingling, double vision, loss of balance and dropping things.

Participants described undergoing a series of medical tests before a diagnosis was made. Using current techniques, this process typically lasts no more than a few weeks. During these weeks, most participants called in sick at work. The reasons for this varied: hospital appointments being scheduled during working hours; people feeling overwhelmed by emotions like anxiety, confusion and stress during the diagnostic process; physical complaints; low energy; or side effects associated with prednisolone treatment commonly administered during a relapse.

Although the diagnosis had turned everyone's world upside down, its timing and impact depended on the type and severity of the experienced symptoms. The stories of the participants suggest that the diagnosis only became truly meaningful when physical and/or cognitive symptoms started impeding their daily (professional) activities.

I followed a two-year rehabilitation project with a psychologist; exercises, an all-in package so to speak. That has given me some peace, but still you have to go through the things yourself and see how you fit your MS into your life. In the beginning, I was like 'What MS? I'll just keep going!' but you often have to face the facts, and then you have to learn to adapt to what your body says. (...) It's important to make choices; it's just every time deliberating on how to handle it. (...) Sometimes my body still surprises me, it's a constant battle with your body. I think I succeeded, finally, but there are still situations that I think: and now I'm the boss (...) Now I realize that MS is more the boss than I would have wanted and if I don't accept that, I will feel it. (Participant 8) 
Becoming familiar with the disease was described as a voyage of discovery, in which boundaries, i.e. what is still possible given the limitations imposed by the disease, were explored. Many stories contained episodes in which participants had to report in sick due to overburdening themselves, often labelled as 'burn-out'. It felt to them like an iterative process of trial and error, as symptoms could vary and a relapse could suddenly bring the disease back to the forefront, requiring further adjustments.

Everything that happens to you is like a learning process that you have to go through. It gets hard when symptoms occur again. When it's kind of stable you can put it to the background giving you the feeling that nothing is going on. But then you encounter new complaints, things that you've never had before and that scares me. Recently, I was really shocked when in September I suddenly didn't feel my arm anymore; that was awful. (Participant 11)

Any sense of familiarity was always partial, because the disease could suddenly manifest itself differently. Participants indicated that the process of becoming familiar with the disease was primarily an individual matter in relation to their body. However, the MS nurse played a significant role in most of the stories and participants reported that knowing some general characteristics of MS felt helpful. Being aware that a relapse and the associated episodic disability was just temporary was reassuring and prevented participants from making rash decisions such as reducing working hours or quitting their job. Participants described both living more in the present, and a process of coming to accept that there were aspects of MS outside of their control. Indeed, besides knowing the fact that MS is incurable, it has so many manifestations that it remained unclear for the participants what the future would hold. One participant described MS as 
a grey zone: it is never black or white and some questions will always be unanswered.

Getting to know the disease was experienced as an emotional, chaotic and intense process in which the participants were preoccupied with their own body. This left little room for reflecting on what the new situation could mean with respect to work.

\section{Adjusting expectations}

When participants had become acquainted with their changed bodies and had experienced what was and what was no longer possible, they were able to start the process of adjustment. In many cases, this was supported by successful disease modifying therapies that stabilized symptoms and allowed concerns regarding the 'sick body' to be shifted more to the background. Conscious decisions about life activities including work had to be made in order to restore a certain balance. This required social and emotional processing, because expectations of (working) life had to be adjusted and long-term career plans and aspirations often had to be altered. Fatigue was the most cited reason for making adjustments.

In the beginning, I didn't see my limits. I always biked to work, seven km, just to show that I could do it, to prove it to myself and to my environment. (...) It was confronting at work; I couldn't remember stuff I had done a hundred times before. That's very hard. I had to ask many things. (...) I would prefer to go back to work and bury my head in the sand. But my mind says that's impossible. Work demands a lot of me now because I don't want to make mistakes, I want to prove myself. But when I come back home I notice that I've passed my limits and that it just takes too much. (Participant 13) 
The changing course of MS meant that expectations frequently needed to be adjusted and therefore any achieved balance was always precarious. Participants felt responsible for adjusting the expectations of their colleagues and line manager, because their symptoms were often invisible and those people were typically unfamiliar with MS.

I think my own role (in retaining work) is ultimately the most important because it obviously has a lot to do with how you position yourself. How open you are about what happens to you (...) how honest you dare to be about what it does to you, physically but also mentally for example. (...) But I think it's especially important to keep communicating, explaining what's going on, why, how you feel about it.' (Participant 7)

That (openness) has become common for me, but that's what I have learned over the years; I have to talk. (...) They (colleagues) don't know how tired I am or how tired I am in my head. (...) You have to learn that, you have to really learn, yes. Because usually, I think to myself, I leave my misery at home. But that doesn't work. Then I will be tired, grumpy and irritable at home. If you do not show them what's really going on inside you, you cannot get the understanding of your colleagues. (Participant 2)

During the early years of their disease and when disease progression was stable, seven participants had taken up a new position, four of whom had to change employers. An excessive workload and the level of physical load were put forward as reasons for this change. The stories showed that although the initiative to change jobs was taken by the participant, there was a heavy dependence on opportunities within the organization and especially on the willingness of the employer. Not every employer was able to empathize and see alternative possibilities.

If I hadn't suggested it myself... they said they were glad I came up with something. They didn't see the link between someone who's working with 
customers and someone at the audit department. Apparently, that didn't make sense to them while I find it completely logical. Well, it's not up to one or the other. You have to do it together and you should have a willingness from both sides to give it shape. (Participant 14)

\section{The understanding and realistic line manager}

The process of becoming familiar with the disease emerged as a predominantly individual process. However, the line manager played a significant role in allowing the participants to invest time and effort in this process and in enabling the necessary adjustments. With one exception, all participants thought it was appropriate to inform their line manager of their diagnosis and considered disclosure a prerequisite for understanding. They often added that the line manager was already aware of existing symptoms. One participant with a temporary contract at the time of diagnosis decided to postpone disclosure until she had a fixed contract. Retrospectively, participants valued the time and space they had received from their line manager during the onset of MS to become familiar with the disease. In some cases, this was imposed upon them.

The first symptoms occurred in September. In October, my line manager called me in sick for a few hours a day because she thought I was acting weird in the afternoon. (...)

Interviewer: Did it make sense to you what she (line manager) said? Not at that time ... but now retrospectively, yes. I do understand now what she said, but at that moment I thought, that it was not too bad ... But now I realize she was right. She could explain it well. (...) Interviewer: But at that time... No, at that time I didn't recognize that... but then I had so many crazy things, so many complaints at the same time that I was a bit dazed... not really aware of the fact that I was acting differently in the afternoon than in the morning... I didn't think about that at all. (Participant 3) 
Participants described an understanding line manager as someone who acknowledged the existence of the disease, was informed about the characteristics of MS, and was attentive to their personal experiences. Participants highlighted that having trust in their line manager facilitated openness in discussing their experiences and concerns, and that this trust had often evolved over a period of time. They also indicated the importance of clear agreements regarding mutual expectations. Having knowledge about (RR)MS enabled the line manager to accept the unpredictability of symptoms and resulting sudden illness reports.

The stories described a line manager who took care of the well-being of the employee as someone capable of realistically assessing both the capabilities and limitations of the employees with MS. Because of loyalty towards their line manager and colleagues, participants frequently exceeded the limits imposed by their MS. The line manager, regularly informed by colleagues about the situation, played an important role in putting a brake on the participants.

My manager said: it's done, you should go home. He noticed that I had problems with my commitment and loyalty to my employer.

Interviewer: How was that for you when he said that?

I was glad because I realized that I no longer knew how to get around. It was a relief that he said it. I myself I wouldn't dare say it. My husband had already said a few times that I should stay home, but I felt I had to do things. In hindsight, I'm very grateful for giving me a few months to discover what MS means in my life. Where my limits are and how I can deal as well as possible with these limits. (Participant 6)

\section{Work as meaningful life activity}

Participants indicated that work continued to be important for them, but that it 
was no longer as important as it was before. Additionally, the motivation to make a career in the sense of striving for a higher position decreased, because it was no longer considered to be realistic. The knowledge of stress potentially having detrimental effect on the disease course of MS made participants reappraise their situation and renounce previously held career aspirations.

I think I can put work into better perspective now. Unlike my colleagues, I'm able to hold a more down to earth view. This has no consequences for the quality of my work. I mean, it's not that I don't care at all. Take for example the new computer system that will be introduced within a few months. My colleagues feel terribly worried about it. They're afraid that things won't work out. I think, well, we'll see, let's take each day as it comes. (Participant 18).

In general, participants described adopting a more relaxed attitude towards professional life. Such a change in attitude was necessary to enable them to be able to 'listen' to their bodies and to adjust their expectations accordingly. The participants indicated that in order for work to be a meaningful life activity, a balance should be found between being challenged and having the feeling that their work could be performed satisfactorily. Having the option of working flexible hours and working from home, as well as having work that was not physically demanding, were perceived as supportive to the decision to keep working. The majority of the participants considered a good relationship with their line manager, as well as the perception that they were valued, important for job satisfaction.

Feeling part of society, valued, and appreciated by others were important motivations to continue working as long as possible. The meaning of work was described by many participants as 'participating in the real world'. One 
participant who only worked 3 hours a week at the time of the interview provided an analogy of the mainland and an island:

I've always enjoyed working. Now, I feel as if I stand outside of society. It's like you're on an island, and you see the mainland well, you see what is happening but you're not part of it. You observe it from a distance, how it really is, from the other side. That's how I feel it. (Participant 13).

\section{Strategic considerations}

In the Netherlands, a meeting with an occupational physician takes place once an employee is on sick leave for six weeks or when a chronic illness has been detected. Participants were well aware that the occupational physician was hired by the employer. In their perception, the physician was obviously focused on them being able to function at work, rather than on their broader well-being.

I have the idea that occupational physicians can never be neutral because they are paid by the company. That's my view though. She treated me well but it was not like she understood me. She didn't really listen to me, especially the psychological part, which is also quite invisible and therefore very difficult. I mean, what's the truth? That was a huge difference with my general practitioner and my psychiatrist who understood me really well. (Participant 9).

Moreover, the narratives showed that occupational physicians had little knowledge of MS, and frequently assumed that MS was a progressive disease. This regularly led to misunderstandings and a sense of not being taken seriously.

The legally defined two-year period during which the working relations remain intact, regardless of the actual working hours of the employee, played a key role in the narratives. This measure provided an incentive for the participants to do their utmost to resume working the full hours of their contract. 
At the same time, this caused some participants to go far beyond their limits, often resulting in a full sick leave.

Ijust want to be back at 100\% in October because in January, I'll be on sick leave for two years. And then I'll see how long I'm going to keep that up. I am quite mean in that respect because when I'll be working $100 \%$ for a month my two years will start again. (Participant 1).

If returning to full hours was deemed infeasible, people preferred applying for a partial Work and Income Act, rather than voluntarily reducing the number of working hours. Participants who opted for the latter regretted this in hindsight, because their unemployment benefits would eventually be based on the final salary. Participants found applying for a (partial) Work and Income Act an emotionally difficult and fatiguing process, also because they assumed that it would turn into a permanent situation. For some, however, the declaration of being partially unfit for work had the reassuring effect of knowing that they no longer had to worry about finances. This contributed to setting priorities and enabled them to 'listen to their bodies'.

I no longer have the idea that I have to work no matter what it takes. Now I know that in case I cannot work anymore because of a relapse there will always be a financial safety net. And I don't push myself any longer, I would rather listen to my body. (Participant 2)

MS was a limiting factor when it came to work flexibility. Participants who received a partial benefit indicated that this type of benefit took away the motivation to take on a better paying position, because their benefit would then be reduced. Also, one participant stated that in order to qualify for a higher position one has to give something extra and this extra is precisely the problem for those living with MS. Participants who were fully employed also indicated 
that they would find it difficult to change employer. A new job would endanger the precarious balance and the relatively secure financial situation achieved in their current job. Moreover, the unpredictable course of MS would make this even more of a leap into the unknown.

I would find it scary to start a new job now. In that case, you have to start with a one-year contract. If something happens in that year... I'll lose everything. I mean, I currently have really good disability insurance. What I don't want is that everything falls apart. (Participant 17)

\section{Discussion}

The aim of this study was to gain insights into the meaning of work in the everyday lives of people with RRMS, and the barriers and facilitators to staying in work. The narratives in our study showed that for people with RRMS, continuing to work was the result of a dynamic process that they could partly influence and that can be described as living in a state of precarious balance that can easily be disturbed. The analysis of the narratives yielded several themes that influenced this balance. Since we focused on people who are still working, the analysis particularly revealed themes that facilitate employment and to a lesser extent the impeding factors.

The first theme, becoming familiar with the disease, indicates that the diagnosis of MS marks the beginning of a voyage of discovery in which individuals have to refamiliarize themselves with their own body. How people deal with the diagnosis of MS is considered an important factor for job retention. Hitherto, however, this process has been approached as merely a cognitive and psychological matter (19-22). The lived relation to one's own body has rarely been thematised. Our study agrees with other qualitative studies on the 
experience of MS that highlight that in everyday life mind and body cannot be separated (23-28). Our participants indicated that they had managed - by trial and error - to learn 'to listen to their (changed) body', and considered this vital to continue working in a sustainable way and not to overburden themselves. Similar experiences have been described in the literature using the concept of body awareness: the felt and immediate experience of one's own body $(29,30)$. Several studies show that improved body awareness of people with a chronic disease may change their attitude to their own body, enhances their ability to listen to bodily symptoms, and increases their sense of control (31-33). Our study emphasizes the importance of the MS nurse or a psychologist in this respect, and indicates that the occupational physician could play a more supportive role than he or she currently does.

Our findings corroborate quantitative studies that have established that receiving symptom-stabilizing treatment supports job retention $(34,35)$. Due to the medication, the unpredictable body became slightly less unpredictable. This supported the participants in making the necessary adjustments. Participants in our study saw the management of expectations in their professional relationships as their own responsibility. Being open about what the disease meant for them was a prerequisite for receiving the understanding they sought from colleagues and superiors, in particular from their line manager. Sweetland et al. (2007) describe two key needs of people with MS for vocational rehabilitation services: managing performance and managing expectations (11). Our study underlines the importance of these two issues as well for job retention among people with MS. 
The third theme shows overlap with other studies that emphasize the key role of the line manager in, and the positive impact of early disclosure on maintaining employment status (36-40). The way that our participants described the role of an understanding line manager is in line with the assertion of Beatty and Joffe (2006) that compassionate line managers are important in accommodating employees with chronic illnesses (41). Compassion means that line managers are aware of both job-related and psychological effects of chronic illness, in particular its variable and long-term nature, and that they respect an employee's autonomy and individuality. What our study adds is that compassion should be accompanied with realism. A line manager should make a realistic assessment of both the employees capabilities and their limitations. Employees with MS are dependent on their line manager in several respects, and trust is an essential prerequisite for a sustainable working relationship. Dejours and Gernet (2012) have emphasized the importance of the building of trust within the context of work (42). Researchers studying employment and RRMS should take these relational aspects into account in their work.

Employment of people with MS has been described as a cost-benefit economy; the benefits should outweigh the costs, both figuratively and literally (43). The narratives demonstrate the inherent challenges of finding a balance between creating a work role that provides job satisfaction and one that respects the employee's current capacities. This is in line with current literature on selfefficacy and work ability $(5,44)$. Also, the changed meaning of work as described by the participants confirms the idea that people with a chronic condition often shift from objective to subjective measures of career success (41). 
Long-term financial stability appears to be an important source of motivation for people with RRMS to do everything possible to remain at work. Although providing stability is the goal of Dutch social legislation, some of the narratives show the unintended effect of the rule that the height of the (partial) benefits is based on the last earned salary. As a result, people are inclined to go beyond their limits, thereby risking overburdening and an early departure from the work force. Other participants indicate that their partial benefits limit flexibility, and as such interfere with experiencing work as meaningful. This can have a detrimental effect on the cost-benefit balance. This issue should be further investigated, taking into account the (inter)national context of the social security system.

For people with MS, remaining in the workforce is a dynamic process that requires a number of interacting factors. For example, an understanding line manager can enable individuals to develop an understanding of the impact of their diagnosis on their work activities, and can support any necessary adjustments. The duration and shape of this process varies, but its start should come shortly after the diagnosis. Whereas for some reducing the work pressure is sufficient, for others it is necessary to stop working entirely for some time. Also, meaningful work and financial reward are a prerequisite for the required commitment. The current sample varied greatly in terms of years since MS diagnosis. Our findings show that the process of balancing continues throughout their careers. Indeed, symptoms may change suddenly, as may the work environment. Our findings suggest there is no one-size-fits-all solution for job retention for people with MS. However, they do provide a direction for rehabilitation practices. Rehabilitation professionals often focus on physical 
rehabilitation and functional aspects of the body $(45,46)$. Our study shows that processes of meaning-making and body awareness should also be addressed. This would enable the identification of appropriate interventions.

We identified three limitations of our study. First, the results are only applicable to a specific sub-type of MS, namely RRMS. The participants in this study had few overt disabilities, and suffered primarily from fatigue and cognitive limitations. Our findings may not apply to more physically disabled people, such as patients with secondary progressive or primary progressive MS. Second, our findings may not be generally applicable to the working population, i.e. to other types of job responsibilities and educational levels. The majority of the participants worked in health care, education, and social services and twelve were highly educated. Thirteen participants worked in an office environment but the type of job responsibilities varied greatly. Third, the sample size was relatively small and varied greatly in terms of years since the diagnosis. Nevertheless, the data reached saturation (i.e. no new themes emerged in the later interviews).

Our study shows that people with a diagnosis of relapsing-remitting Multiple Sclerosis have to refamiliarize themselves with their own body in a meaningful way to be able to continue their work. Medication that stabilises symptoms can support people with MS in making the necessary adjustments in their private and working life. A trusting relationship with the line manager is vital to be able to remain at work. Additionally, a balance between being adequately challenged by work, while simultaneously having the capacity to meet work demands is needed, as is long-term financial stability. 


\section{Acknowledgements}

\section{Declaration of interest}

There are no conflicts of interest.

\section{References}

1. Thomas PW, Thomas S, Kersten P, Jones R, Nock A, Slingsby V, et al. Multi-centre parallel arm randomised controlled trial to assess the effectiveness and cost-effectiveness of a group-based cognitive behavioural approach to managing fatigue in people with multiple sclerosis. BMC Neurol. 2010;10:43.

2. Coyne KS, Boscoe AN, Currie BM, Landrian AS, Wandstrat TL. Understanding Drivers of Employment Changes in a Multiple Sclerosis Population. Int J MS Care. 2015;17(5):245-52.

3. Rumrill, P.D. Hennessey, M.L. Nissen SW. Employment issues and multiple sclerosis. New York: DemosHealth; 2008.

4. Bøe Lunde HM, Telstad W, Grytten N, Kyte L, Aarseth J, Myhr KM, et al. Employment among patients with multiple sclerosis-A population study. PLoS One. 2014;9(7):1-7.

5. van der Hiele K, van Gorp DAM, Heerings MAP, van Lieshout I, Jongen PJ, Reneman MF, et al. The MS@Work study: A 3-year prospective observational study on factors involved with work participation in patients with relapsing-remitting Multiple Sclerosis. BMC Neurol. 2015;15(1):1-8.

6. Julian LJ, Vella L, Vollmer T, Hadjimichael O, Mohr DC. Employment in multiple sclerosis: Exiting and re-entering the work force. J Neurol. 2008;255(9):1354-60.

7. Fryers T. Work, identity and health. Clin Pract Epidemiol Ment Heal. 2006;2(12).

8. Kirk, J. Wall C. Work and Identity: Historical and Cultural Contexts. UK: Palgrave Macmillan; 2011.

9. Roessler RT, Rumrill PD J. Multiple sclerosis and employment barriers: a 
systematic perspective on diagnosis and intervention. Work. 2003;21(1):17-23.

10. Bishop M, Rumrill PD. Employment and community living issues for people with Multiple Sclerosis. Work. 2015;52:723-4.

11. Sweetland J, Riazi A, Cano SJ, Playford ED. Vocational rehabilitation services for people with multiple sclerosis: what patients want from clinicians and employers. Mult Scler. 2007;13(9):1183-9.

12. Vickers MH. Why people with MS are really leaving work. Rev Disabil Stud An Int J. 2008;4(4):43-57.

13. Sweetland, J. Howse, E. Playford ED. A systematic review of research undertaken in vocational rehabilitation for people with multiple sclerosis. Dis Rehabil. 2012;34(24):2031-8.

14. Compston A, Coles A. Multiple sclerosis. Lancet. 2002;359(9313):122131.

15. Riessman CK. Narrative methods for the human sciences. Los Angeles Sage Publications; 2008.

16. Polman CH, Reingold SC, Banwell B, Clanet M, Cohen J a., Filippi M, et al. Diagnostic criteria for multiple sclerosis: 2010 Revisions to the McDonald criteria. Ann Neurol. 2011;69(2):292-302.

17. McCormack $\mathrm{C}$, Methods F. From Interview Transcript to Interpretive Story: Part 2-- Developing an Interpretive Story. Field methods. 2000;12(4):298-315.

18. Barbour RS. Checklists for improving rigour in qualitative research: a case of the tail wagging the dog? BMJ. 2001;322:1115-7.

19. Van Denend T. Employment needs of people with multiple sclerosis: a review of current literature and application to occupational therapy practice. Occup Ther Heal Care. 2006;20(1):61-77.

20. Varekamp I, Heutink A, Landman S, Koning CEM, De Vries G, Van Dijk FJH. Facilitating empowerment in employees with chronic disease: Qualitative analysis of the process of change. J Occup Rehabil. 
2009;19(4):398-408.

21. Varekamp I, Krol B, Van Dijk FJH. Empowering employees with chronic diseases: Process evaluation of an intervention aimed at job retention. Int Arch Occup Environ Health. 2011;84(1):35-43.

22. Devy R, Lehert P, Varlan E, Genty M, Edan G. Improving the quality of life of multiple sclerosis patients through coping strategies in routine medical practice. Neurol Sci. 2015;36(1):85-90.

23. Finlay L. The intertwining of body, self and world: A phenomenological study of living with recently-diagnosed multiple sclerosis. J Phenomenol Psychol. 2003;34(2):157-78.

24. Toombs SK. Reflections on bodily change: the lived experience of disability. In: Toomb S, editor. Handbook of phenomenology and mediicine. Dordrecht: Kluwer Academic Publishers; 2001. p. 247-62.

25. De Ceuninck van Capelle, A., Visser, L.H., Vosman F. Developing patient-centred care for multiple sclerosis (MS). Learning from patient perspectives on the process of MS diagnosis. Eur J Pers Centred Healthc. 2016;4(4).

26. Svenaeus F. The body uncanny-further steps towards a phenomenology of illness. Med Heal Care Philos. 2000;3(2):125-37.

27. Alzhén R. Illness as unhomelike being-in-the-world. Phenomenology and medical practice. Med Heal Care Philos. 2011;14(3):323-31.

28. Gadow S. Body and self: a dialectic. J Med Philos. 1980;5(3):172-85.

29. Mehling WE, Gopisetty V, Daubenmier J, Price CJ, Hecht FM, Stewart A. Body awareness: Construct and self-report measures. PLoS One. 2009;4(5).

30. Mehling WE, Wrubel J, Daubenmier JJ, Price CJ, Kerr CE, Silow T, et al. Body Awareness: a phenomenological inquiry into the common ground of mind-body therapies. Philos Ethics Humanit Med. 2011;6(1):6.

31. Lööf H, Johansson UB, Henriksson EW, Lindblad S, Bullington J. Body awareness in persons diagnosed with rheumatoid arthritis. Int J Qual Stud 
Health Well-being. 2014;9:24670.

32. Afrell M, Biguet $\mathrm{G}$, Rudebeck CE. Living with a body in pain - Between acceptance and denial. Scand J Caring Sci. 2007;21(3):291-6.

33. Gard G. Body awareness therapy for patients with fibromyalgia and chronic pain. Disabil Rehabil. 2005;27(12):725-8.

34. Lage, M.J., Casatelli-Haley, J., Oleen-Burkey MA. Effect of immunomodulatory therapy and other factors on employment loss time in multiple sclerosis. Work. 2006;27:143-51.

35. Ziemssen, T., Hoffman, J., Apfel, R., Kern S. Effects of glatiramer acetate on fatigue and days of absence from work in first-time treatment relapsing-remitting multiple sclerosis. Heal Qual Life Outcomes. 2008;6(67).

36. Jellie B, Sweetland J, Riazi A, Cano SJ, Diane E. Staying at work and living with MS: a qualitative study of the impact of a vocational rehabilitation intervention. Dis Rehabil. 2014;36(19):1594-9.

37. Abma, F.I. Bultmann, U., Varekamp, I. van der Klink JJ. Workers with health problems: three perspectives on functioning at work. Disabil Rehabil. 2013;35(1):20-6.

38. Holmgren, K. Dahlin Ivanoff S. Supervisors' views on employer responsibility in the return to work process. A focus group study. J Occup Rehabil. 2007;17(1):93-106.

39. Kirk-Brown A, Van Dijk P, Simmons R, Bourne M, Cooper B. Disclosure of diagnosis of multiple sclerosis in the workplace positively affects employment status and job tenure. Mult Scler J. 2014;20(7):871-6.

40. Abma FI, Bültmann U, Varekamp I, van der Klink JJL. Workers with health problems: Three perspectives on functioning at work. Disabil Rehabil. 2013;35(1):20-6.

41. Beatty JE, Joffe R. An Overlooked Dimension Of Diversity:. The Career Effects of Chronic Illness. Organ Dyn. 2006;35(2):182-95.

42. Dejours, C., Gernet I. “Travail, subjectivite et confiance.” Nouv Rev 
psychosociologie. 2012;1(13):75-91.

43. Johnson KL, Yorkston KM, Klasner ER, Kuehn CM, Johnson E, Amtmann D. The Cost and Benefits of Employment: A Qualitative Study of Experiences of Persons with Multiple Sclerosis. Arch Phys Med Rehabil. 2004;85(2):201-9.

44. Jongen PJ, Ruimschotel R, Heerings M, Hussaarts A, Duyverman L, van der Zande A, et al. Improved self-efficacy in persons with relapsing remitting multiple sclerosis after an intensive social cognitive wellness program with participation of support partners: a 6-months observational study. Health Qual Life Outcomes. 2014;12(1):40.

45. Somerset M, Campbell R, Sharp DJ, Peters TJ. What do people with MS want and expect from health-care services? Heal Expect. 2001;4(1):2937.

46. Capelle ADC Van, Visser LH, Vosman F. Multiple Sclerosis and Work: An Interpretative Phenomenological Analysis of the Perspective of Persons with Early Stage MS. J Mult Scler. 2015;2(4). 
Table 1. Participant demographics

\begin{tabular}{|c|c|c|c|c|c|c|c|}
\hline $\begin{array}{l}\text { Participant } \\
\text { code }\end{array}$ & Gender & $\begin{array}{l}\text { Age } \\
(\mathrm{yrs})\end{array}$ & $\begin{array}{l}\text { Years } \\
\text { since } \\
\text { diagnosis }\end{array}$ & $\begin{array}{l}\text { Prior } \\
\text { employment } \\
\text { status }\end{array}$ & $\begin{array}{l}\text { Employment } \\
\text { status } \\
\text { current } \\
\text { contract }\end{array}$ & $\begin{array}{l}\text { Actual } \\
\text { working }\end{array}$ & Occupation \\
\hline 1 & F & 40 & 2 & $20 \mathrm{~h} / \mathrm{w}$ & $20 \mathrm{~h} / \mathrm{w}$ & $85 \%$ & $\begin{array}{l}\text { Vocational } \\
\text { teacher }\end{array}$ \\
\hline 2 & F & 55 & 12 & $32 \mathrm{~h} / \mathrm{w}$ & $20 \mathrm{~h} / \mathrm{w}$ & $100 \%$ & $\begin{array}{l}\text { Elementary } \\
\text { school } \\
\text { counsellor }\end{array}$ \\
\hline 3 & F & 29 & 2 & $40 \mathrm{~h} / \mathrm{w}$ & $15 \mathrm{~h} / \mathrm{w}$ & $100 \%$ & $\begin{array}{l}\text { Workforce } \\
\text { reintegration } \\
\text { assistant }\end{array}$ \\
\hline 4 & F & 53 & 11 & $16 \mathrm{~h} / \mathrm{w}$ & $20 \mathrm{~h} / \mathrm{w}$ & $100 \%$ & $\begin{array}{l}\text { Elderly care } \\
\text { assistant }\end{array}$ \\
\hline 5 & F & 40 & 3 & $30 \mathrm{~h} / \mathrm{w}$ & $28 \mathrm{~h} / \mathrm{w}$ & $50 \%$ & $\begin{array}{l}\text { Legal } \\
\text { assistant }\end{array}$ \\
\hline 6 & $\mathrm{~F}$ & 35 & 2 & $30 \mathrm{~h} / \mathrm{w}$ & $18 \mathrm{~h} / \mathrm{w}$ & $100 \%$ & $\begin{array}{l}\text { Policy } \\
\text { advisor }\end{array}$ \\
\hline 7 & M & 46 & 7 & $40 \mathrm{~h} / \mathrm{w}$ & $36 \mathrm{~h} / \mathrm{w}$ & $100 \%$ & $\begin{array}{l}\text { Business } \\
\text { developer }\end{array}$ \\
\hline 8 & $\mathrm{~F}$ & & 10 & $40 \mathrm{~h} / \mathrm{w}$ & $20 \mathrm{~h} / \mathrm{w}$ & $100 \%$ & Secretary \\
\hline 9 & $\mathrm{~F}$ & 41 & 9 & $32 \mathrm{~h} / \mathrm{w}$ & $24 \mathrm{~h} / \mathrm{w}$ & $70 \%$ & $\begin{array}{l}\text { Workforce } \\
\text { reintegration } \\
\text { assistant }\end{array}$ \\
\hline 10 & $\mathrm{~F}$ & 42 & 5 & $24 \mathrm{~h} / \mathrm{w}$ & $15 \mathrm{~h} / \mathrm{w}$ & $100 \%$ & Job coach \\
\hline 11 & $\mathrm{~F}$ & 48 & 2 & $16 \mathrm{~h} / \mathrm{w}$ & $16 \mathrm{~h} / \mathrm{w}$ & $100 \%$ & $\begin{array}{l}\text { Care home } \\
\text { caregiver }\end{array}$ \\
\hline 12 & $\mathrm{M}$ & 53 & 11 & $40 \mathrm{~h} / \mathrm{w}$ & $20 \mathrm{~h} / \mathrm{w}$ & $100 \%$ & $\begin{array}{l}\text { Vocational } \\
\text { teacher }\end{array}$ \\
\hline 13 & F & 46 & 2 & $38 \mathrm{~h} / \mathrm{w}$ & $38 \mathrm{~h} / \mathrm{w}$ & $8 \%$ & $\begin{array}{l}\text { Service } \\
\text { representative } \\
\text { DIY store }\end{array}$ \\
\hline 14 & M & 48 & 6 & $40 \mathrm{~h} / \mathrm{w}$ & $32 \mathrm{~h} / \mathrm{w}$ & $100 \%$ & $\begin{array}{l}\text { Process } \\
\text { controller }\end{array}$ \\
\hline 15 & M & 50 & 25 & $40 \mathrm{~h} / \mathrm{w}$ & $20 \mathrm{~h} / \mathrm{w}$ & $100 \%$ & $\begin{array}{l}\text { Vocational } \\
\text { teacher }\end{array}$ \\
\hline
\end{tabular}




$\begin{array}{llllllll}16 & \mathrm{M} & 52 & 32 & 40 \mathrm{~h} / \mathrm{w} & 40 \mathrm{~h} / \mathrm{w} & 100 \% & \begin{array}{l}\text { Professional } \\ \text { soldier }\end{array} \\ 17 & \mathrm{~V} & 46 & 18 & 32 \mathrm{~h} / \mathrm{w} & 32 \mathrm{~h} / \mathrm{w} & 100 \% & \begin{array}{l}\text { Project } \\ \text { manager }\end{array} \\ 18 & \mathrm{~V} & 49 & 6 & 18 \mathrm{~h} / \mathrm{w} & 18 \mathrm{~h} / \mathrm{w} & 100 \% & \begin{array}{l}\text { Library staff } \\ \text { member } \\ 19\end{array} \\ & \mathrm{M} & 55 & 6 & 40 \mathrm{~h} / \mathrm{w} & 40 \mathrm{~h} / \mathrm{w} & 50 \% & \begin{array}{l}\text { Academic } \\ \text { professor }\end{array}\end{array}$

Prior employment status: employment status prior to the diagnosis MS.

Employment status current contract: number of working hours per week according to the current labour contract.

Actual working: actual working hours during the time of the interview as a percentage of the current labour contract. 
Table 2 Titles of narratives as given by participants

- Working on and with my MS

- Change

- My life since the diagnosis of MS

- Life is like riding a bicycle. To keep your balance, you must keep moving

- My Story. MS, so what? I just keep going!

- Continue working with MS can only be realized when necessary adjustments are realized

- Diagnosis of MS, but I remain who I am

- MS for 12 years and I still walk...

- Continue working with MS is only possible with commitment and understanding of employee and employer

- Keep enjoying life

- How I have struggled during the diagnosis and afterwards

- How MS changes your life

- Always looking for a new balance 
Table 3 Thematic analysis narrative interviews: motives and explanations to continue working provided by 19 participants with RRMS

Theme

1. Becoming familiar with the disease

2. Adjusting expectations
Subthemes

- The strange body

- Dealing with uncertainty

- Exploring boundaries

- Acting in accordance with boundaries

- Openness in the workplace

- Joint process and relying on each other

- Precarious balance

3. The understanding and realistic line manager

4. Work as meaningful life activity

5. Strategic considerations
- Leaving room for uncertainty

- $\quad$ Trusting relationship

- Taking care of the well-being of the employee

- Clear agreements

- Changing meaning of work

- Being part of society and being meaningful

- Job satisfaction

- Occupational health service

- Financial motives

- $\quad$ Limited flexibility 
